photocopying process which is commendably speedy but also provokes migraine in susceptible readers. The conference language was English-the editors were not!

R. W. ROSS RUSSELL

Pathology of Peripheral Nerves By R. O. Weller and J. Cervós-Navarro. (Pp. 225; illustrated; £13.50.) Butterworths: London and Boston. 1977.

This book attempts to fill a loophole between the works on neuropathology and muscle pathology, and deals, in the middle third of its 214 pages, with general pathology of peripheral nerve and the pathology of peripheral nerve diseases. This has been no easy task for it is difficult to think of the nerves in disease without considering their cell bodies, synapses, and specialised endings. Where necessary, brief references are macle to these matters while concentrating on the results of biopsy or necropsy studies of nerves. The technique of sural nerve biopsy and the ruinous consequences of inexpert handling are described. The laboratory work is not dealt with in detail but each technique is covered by references to original descriptions or standard laboratory technical books.

For the majority of those who would be attracted by the title of this book the technical section may seem unrewarding and the final third of the book, devoted to descriptions of tumour pathology which are available elsewhere, may seem unbalanced.

This volume is highly priced for what it yields, but it will probably be welcomed by laboratories with neurological interests because it brings together many references to widely scattered old and very new work on axonal injury, regeneration, "dyingback", myelination, dysmyelination nodes and internodes, and Schwann cell biology.

DAVID DOYLE

Multiple Sclerosis-A Critical Conspectus Edited by E. J. Field. (Pp. 265; illustrated; £9.95.) MTP Press: Lancaster. 1977.

The stated purpose of this small, multiauthored book is to highlight "the shortcomings of our approaches" to the study of multiple sclerosis, to help the general physician understand why neurologists have failed to solve the problem, and to direct the attention of young neurobiologists towards this illness. Unfortunately, our ignorance of multiple sclerosis is still all too apparent and, with so many excellent monographs and publications on the subject available, I cannot see why this book was produced. Most of the experimental virological and immunological data given are highly controversial and would not be accepted by the majority of established workers in the field. I find the clinical account poor, since it adds nothing and tends towards the anecdotal. The research worker will not require this book, the clinician unaware of the existing controversies will be confused by it, and the novice will be misled. I cannot recommend it.

PETER O. BEHAN

Remembering Henry Edited by Stephen Lock and Heather Windle. (Pp. 166; £3.00.) British Medical Association: London. 1977.

\section{THE GREAT CHAM}

Portrait painters as opposed to mere photographers inevitably incorporate into their works the fundamental features of their own personalities. Most Johnsonians discern in Boswell's "Life" of his great master all the elements of the writer's own character. This present collection of written portraits, engagingly assembled by Stephen Lock and Heather Windle, has produced a distillate, at once fascinating and charming, of the subtle emotional and intellectual forces at work between the subject and the authors. It is truly a homely Festschrift (how Henry himself would have castigated that turgid term!), for this splendid volume, dedicated to the memory of a remarkable ornament of the neurological and academic scene, recalls vividly to those who knew him, and evokes for those whose misfortune was not to have done so, all the charisma of a unique personality. The enterprise, whether by design or happy accident, succeeds beyond expectation, for each contribution springs from the special relationship established between each of the writers and their mutual subject, and so creates a true hologrammatic image of a man whom they (and we) knew and cherished. The contributions range from the austere, and not always uncritical, appreciation through personal devotion and at times justifiable frank idolaty It would be invidious to select an particular section for special ment廉 Suffice it to say that all are eminem readable and occasionally quite है। roarious.

The three final sections of the mogic graph are selections from Henry's of writing-his account of accident neutr sis, his essay on medical education $\overrightarrow{\text { gr }}$ titled "Fifty years after Flexner", an finally that devastating broadside fi in response to what one can on assume to be a wilful masochisti invitation to the World Psychiatid Symposium of 1969 and entitled "Ps chiatry-medicine or magic?"

If you have not already bought book, send a minion out at once $t$ collect it. It will please you too. L. A. LIVERSED $\overrightarrow{\mathrm{G}}$

\section{Notices}

An International Symposium on ipheral Neuropathies will be heफd oq Milan, Italy from 26 to 28 June Enquiries should be addressed to th Secretariat, Symposium on Periphers Neuropathies, Ospedale S. Rapaes 20090 Segrate (Milan) Italy. Teleshon 02-2134041.

On the occasion of the 50 year Jubite of Aarhus University a Symposium Nervous System Abnormalities Nervous Diseases in Diabetes Melligu will be held from 31 August to $1 \mathrm{~S}$ tember 1978. A limited number of shor free communications will be accepted For further information please write Professor K. Lundbæk, 2nd Universi Clinic of Internal Medicine, Kommuñe hospitalet, 8000 Aarhus C, Denmark

The 4th International Symposium Microsurgical Anastomoses for Cerebra Ischemia will be held in Lond\&n Ontario from 6 to 8 September 1978 Neurosurgeons and other neuroscientist: interested in the problems of cerebra ischemia and revascularisation of brain are invited to participate. information please write to $S$. J. Peer less, MD, FRCS(C), Division of Neuro surgery, University Hospital, Box 53 Terminal "A", London, Ontario. No 5A5 Canada. 